\title{
Financial reimbursement - irrelevant for GPs' readiness to implement brief intervention to reduce alcohol consumption? A cross-sectional vignette study
}

Thomas Fankhaenel ${ }^{1,2^{*}}$, Katrin Schulz ${ }^{2}$, Lars-Eric Petersen ${ }^{1}$, Andreas Klement ${ }^{1}$ and Thomas Frese ${ }^{1}$

\begin{abstract}
Background: General Practitioners' (GPS) readiness to implement screening and brief intervention (SBI) to treat patients with excessive alcohol consumption is low. Several studies identified crucial barriers such as insufficient financial reimbursement. In contrast to the barriers-account, we assume that low implementation readiness of GPs may be less attributed to external barriers but rather more so to inherent characteristics of SBI. To test our assumption, we conducted a vignette study assessing the GPs' readiness to implement SBI in comparison to a pharmacological intervention also designed for the treatment of excessive drinkers in relation to standard or abovestandard financial reimbursement. According to our hypothesis GPs should be less ready to implement SBI regardless of financial reimbursement.
\end{abstract}

Methods: A convenience sample of GPs was recruited to answer the questionnaire. To assess the GPs' implementation readiness a 4-item 6-point Likert scale was developed and pretested.

Results: One hundred forty GPs completed the questionnaire. GPs were more ready to implement the pharmacological intervention than $\mathrm{SBI}, F(1,132)=27.58, p<.001$ (main effect).

We found no effect for financial reimbursement, $F(1,132)=3.60$, ns, and no interaction effect, $F(1,132)=2.20$, ns.

Conclusions: Further research should investigate more thoroughly the crucial characteristics of SBI to initiate a modification process finally leading to more effective primary care dependency prevention.

Keywords: General practitioner, Screening and brief intervention (SBI), Excessive alcohol consumption, Financial reimbursement

\footnotetext{
* Correspondence: thomas.fankhaenel@srh.de

'University of Halle-Wittenberg, Halle, Germany

${ }^{2}$ SRH University of Applied Health Sciences, Gera, Germany
}

(C) The Author(s). 2020 Open Access This article is licensed under a Creative Commons Attribution 4.0 International License, which permits use, sharing, adaptation, distribution and reproduction in any medium or format, as long as you give appropriate credit to the original author(s) and the source, provide a link to the Creative Commons licence, and indicate if changes were made. The images or other third party material in this article are included in the article's Creative Commons licence, unless indicated otherwise in a credit line to the material. If material is not included in the article's Creative Commons licence and your intended use is not permitted by statutory regulation or exceeds the permitted use, you will need to obtain permission directly from the copyright holder. To view a copy of this licence, visit http://creativecommons.org/licenses/by/4.0/ The Creative Commons Public Domain Dedication waiver (http://creativecommons.org/publicdomain/zero/1.0/) applies to the data made available in this article, unless otherwise stated in a credit line to the data. 


\section{Background}

Preventive approaches such as screening and brief intervention (SBI) have been shown to be effective in reducing alcohol consumption in general practice patients [1] [2]. Brief intervention (BI) in the form of feedback, information, and advice for patients screening positive has been thus recommended to German General Practitioners (GPs) [3]. Nonetheless most GPs do not implement BI into their routine care [4] [5] [6] [7]. To identify barriers against implementation, several studies have been conducted [8] [9] [10] [11] [12] [13] [14] [15] identifying a large number of barriers subsumed to categories including organizational factors (e.g. lack of financial incentives), staff factors (e.g. lack of knowledge), patient factors (e.g. negative reaction in terms of embarrassment or unease) [1], individual level factors (lack of education), or society-level factors (heterogeneous understanding of the alcohol problem) [13]. This remarkable number of barriers can be interpreted in at least two different ways. It can be interpreted first as the disclosure of SBI as a badly designed and possibly too demanding treatment not feasible for the target group of excessive drinkers in primary care. It can also be interpreted however as an indicator of the GPs' uncertainty regarding what prevents them from implementing a well efficacious intervention.

To advance the discourse we want to suggest a change of perspective. We believe that talking in terms of barriers implicates that an aspired activity - implementing a brief intervention for patients who screened positive - is not translated into action because of one or more barriers preventing the GP - from implementing it. If so, the elimination of those barriers should result in action and widespread implementation of SBI in primary care. However, only small effects were found by modifying external conditions such as reimbursement. Although for example an experimentally introduced reimbursement led to improved implementation (fee for service), and implementation declined after terminating the reimbursement [16], we presume nonetheless that barriers such as lack of or insufficient financial reimbursement are not the major problem. Other research seems to support this position [17] [18].

In contrast to the barriers-account we presume that inherent characteristics of BI may be understood as the primary problem. BI should be implemented in an empathetic, respectful, positive relationship with the patient. GPs should work with the person's own ideas, concerns and motivations by using active listening skills, including open-ended questions, and affirmations in order to encourage the patients to take personal responsibility for their decisions [3]. These conditions may cause GPs to worry about being overwhelmed. For instance, GPs may be possibly forced to convince excessive drinkers to reduce their alcohol consumption by means of advice and gentle forms of persuasive communication (e.g. Motivational Interviewing [19]) in the worst case resulting in a debate with difficult to refute disagreement, hostile response, or respectively feigned compliance [15]. We assume moreover that such negative expectations may be less probable when using an intervention without those demanding characteristics. To test our hypothesis in this study half of the GPs were asked to assess their readiness to implement BI whereas the other half were asked to assess their readiness to implement a pharmacological intervention (PI) also designed to reduce the alcohol consumption of excessive drinkers (nalmefene [20]). Additionally, the effect of intervention type, BI versus PI, should be compared with the effect of an above-standard financial reimbursement. According to our hypothesis we expected that GPs would report being more ready to implement the PI regardless of financial reimbursement.

\section{Methods}

\section{Design and setting}

We planned a cross-sectional, randomized vignette study using a 2 (BI vs. PI) $\times 2$ (standard reimbursement versus above standard reimbursement) design. For randomization of GPs we used a PC random generator determining the order of questionnaires. A convenience sample of GP offices in Saxony-Anhalt, Thuringia, Saxony, and Hesse was recruited by conducting a spontaneous visit by a research assistant during opening hours. In an attempt to attain our recruitment goal of 200 participants, 246 GPs practicing in four German federal states were consulted personally at their general practice offices by nine research assistants. On site, the practice nurse was informed about the study and asked about inviting their GP to participate. At the time of GPs' consent to participate, study information, consent forms, questionnaire, and the payment-sheet were handed over to them. The completed study materials were gathered in a follow-up practice visit. Each GP completing the questionnaire received a financial reimbursement of 25 Euro.

\section{Questionnaire}

The questionnaire was developed by an interdisciplinary team of GPs, social scientists, and psychologists experienced in their respective fields of research. It was selfdesigned and development followed the concept of face validity. The questionnaire was pretested by scientifically experienced GPs and the feedback led to minor modifications. A piloting was done with a subsample of eight GPs. After introduction GPs were provided with an equivalent amount of information about either BI or PI for patients with excessive alcohol consumption (first independent variable). In the BI condition GPs were informed about the procedure of screening and brief intervention including information about the AUDIT-C screener and eight randomly selected BI treatment activities such as advising the patient to drink nonalcoholic 
beverages if thirsty or to drink alcohol only in small sips [21]. In the PI condition GPs received information about the pharmacological intervention with nalmefene designed to help patients to reduce their alcohol consumption [22] [20]. Both questionnaires are included in the supplementary material.

GPs of both conditions then read about an identical situation describing a known patients' visit to their general practice. They also read that the consultation raised the suspicion of an excessive alcohol consumption. Finally, GPs were asked to evaluate their readiness to implement the depicted intervention - BI versus PI- under conditions of either standard financial reimbursement or above-standard financial reimbursement (second independent variable). In the standard financial reimbursement condition one half of GPs assessed their implementation readiness in relation to a financial reimbursement of $18 €$ for $20 \mathrm{~min}$ intervention according to the German fee-for-service reimbursement standard [23]. In the above-standard financial reimbursement condition the other half of GPs were asked to assess their implementation readiness in relation to a financial reimbursement twice as high (36 $€)$ for the same length of time.

The GPs' implementation readiness was assessed by a Likert scale ranging from 1 (do not agree) to 6 (do agree) using the following pretested items: 1) For the depicted financial reimbursement (18 vs. $36 €$ ) I would inform the patient with excessive alcohol consumption about the intervention (BI vs. pharmacological intervention); 2) For the depicted financial reimbursement (18 vs. $36 €$ ) I would carry out the intervention for the patient agreeing to participate (BI vs. pharmacological intervention); 3) The intervention (BI vs. pharmacological intervention) is not feasible in my own general practice; 4) The intervention (BI vs. pharmacological intervention) is not effective to reduce the alcohol consumption of excessive drinkers.

For control purposes the GPs' attitude to alcohol problems and their treatment was assessed by using the Short Alcohol and Alcohol Problems Perception Questionnaire (SAAPPQ [24]). The SAAPPQ is a validated measure providing information about the GPs' perceptions of a) the adequacy of their skills and knowledge in relation to problem drinkers (subscale role security) and b) how appropriate it is for them to engage in work with such clients (subscale therapeutic commitment) [24]. It also ranges from 1 (do not agree) to 6 (do agree).

Finally, demographic data and practice information were gathered. SPSS statistical software (version 22.0) was used to calculate means as well as standard deviations and to run $\mathrm{AN}(\mathrm{C})$ OVAs for continuous variables. A statistically significant difference was stated for $p<0.05$.

\section{Results}

Of the 246 GPs who were approached, 200 agreed to participate in the study. Of these, 140 GPs returned the questionnaire. All returned questionnaires were complete and could be analyzed. Mean age of GPs was 50 years $(S D=$ 9.70) with a mean of 15.40 years in practice $(S D=9.13)$. More than half of the GPs were women (66.2\%), 96 managed an urban practice (69.6\%), and 47 worked in a group practice, in a practice sharing or were employed in an ambulatory health care center (34.1\%). The GPs of our sample ran their general practices in 31 cities with a maximum of 22 GPs in Leipzig and a minimum of 1 GP in 20 cities.

GPs' attitude to alcohol problems was assessed by the SAAPPQ questionnaire with a moderate reliability (Cronbachs' alpha $=.68$ ). GPs reported a mean attitude to alcohol problems and their treatment of $4.66(S D=0.61)$. GPs of the BI condition did not differ markedly from GPs of the PI condition regarding age, years in practice, percentage of female participants, urban practices, and attitude towards alcohol problems. The groups differed markedly in the percentage of group practices (see Table 1), even though the group assignment had been random.

Implementation readiness of GPs was assessed by a 4item 6-point Likert scale with also moderate reliability (Cronbachs' alpha $=.72$ ). GPs reported a mean implementation readiness of $4.01(S D=1.37)$. An ANCOVA with intervention (BI/PI) and financial reimbursement (standard/above-standard) as between-subject factors, attitude about alcohol problems (SAAPPQ) and practice type (single/group practice) as covariates and implementation readiness as dependent variable revealed a main effect for intervention, but not for financial reimbursement (see Table 2). GPs were more ready to implement the PI $(M=4.44, S D=1.23)$ in comparison to the $\mathrm{BI}$ $(M=3.39, S D=1.33$; see Table 2$)$. We found furthermore a positive association between the attitude to alcohol problems and the intervention readiness.

\section{Discussion}

Previous research explained the GPs' low readiness to implement $\mathrm{BI}$ for excessive drinkers by pointing out the

Table 1 GP and practice characteristics in the BI and PI condition; subgroups do not differ significantly in any characteristic

\begin{tabular}{|c|c|c|}
\hline & \multicolumn{2}{|l|}{ condition } \\
\hline & $\mathrm{Bl}$ & $\mathrm{Pl}$ \\
\hline Number & 61 & 79 \\
\hline Mean age in years (SD) & $50(10.25)$ & $50(9.33)$ \\
\hline \% women $(\mathrm{N})$ & $62.3(38)$ & $69.2(54)$ \\
\hline Mean years in practice $(\mathrm{SD})$ & $16(9.81)$ & $14.9(8.61)$ \\
\hline$\%$ urban $^{a}$ practices $(\mathrm{N})$ & $72.1(44)$ & $67.5(52)$ \\
\hline$\%$ group practices $^{\mathrm{b}}(\mathrm{N})$ & $43.3 \%(26)$ & $26.9 \%(21)$ \\
\hline
\end{tabular}

adentification as 'urban' or 'rural' practice according to the GPs judgement

${ }^{b}$ Practice sharing and ambulatory health care center are subsumed to group practices 
Table 2 ANCOVA results with main effects for intervention type (BI vs. PI) and GPs' attitudes to alcohol problems (SAAPPQ) regarding implementation readiness

\begin{tabular}{llll}
\hline & $\mathrm{df}$ & $\mathrm{F}$ & $P$-value \\
\hline Intervention (BI/PI) & 1132 & 27.58 & .000 \\
Financial reimbursement (standard/above) & 1132 & 3.60 & .060 \\
GPs' attitudes to alcohol problems (SAAPPQ) & 1132 & 6.31 & .013 \\
Practice type (single/group) & 1132 & 3.11 & .080 \\
\hline
\end{tabular}

large number of implementation barriers. By means of vignette study we tried to show that GPs' low readiness should be explained rather by inherent characteristics of $\mathrm{BI}$ and less by associated barriers such as insufficient financial reimbursement [11]. In our vignette study we tested for the combined effect of the factors intervention type (BI vs. PI) and financial reimbursement (standard vs. above-standard) on the implementation readiness of GPs. We found that GPs' reported readiness to implement BI was lower than their readiness to implement a pharmacological intervention. However, only a tendency that did not reach statistical significance could be found for the second factor (financial reimbursement). GPs trended toward a slightly higher implementation readiness under the condition of above-standard financial reimbursement.

To reduce alcohol consumption several approaches have been created (e.g. Motivational Interviewing [19]). These approaches have been evaluated positively by efficacy studies and are thus recommended for use [1]. It is probably also true that GPs are generally ready to motivate excessive drinkers to reduce their alcohol consumption and they probably know very well about the health costs of excessive drinking [25]. But they are nevertheless not ready to treat these patients with SBI. Although our results were only recorded in Germany, they seem to be valid internationally too. Comparative studies are available, for instance, for Switzerland and France [7], as well as Sweden and the Netherlands [26]. Both studies provide corresponding results. Although Swedish patients received more SBI than Dutch patients, only 6.0\% received advice on how to reduce their alcohol consumption in comparison to $4.7 \%$ in the Netherlands. Moreover, the vast majority of $91 \%$ of French GPs did not use any test to screen for hazardous drinking in comparison to $77 \%$ of Swiss GPs. Even more daunting in this context may be the systematic review about strategies to improve the implementation of SBI [27] including results from 13 countries such as USA, Australia, GBR, and Spain showing that none of the tested strategies showed significant improvement regarding patient outcomes. We believe hence that the substantial number of barriers reported in previous studies indicates some 'deeper' conflict being rooted in the inherent characteristics of BI and we'd like to ask, is the time ripe now to quit forcing the implementation of $\mathrm{BI}$ into routine care?
It was not the intention of our study to show the superiority of pharmacological interventions to treat excessive drinkers and our results should not be understood as recommendation to prefer this type of intervention to BI. Pharmacological interventions to reduce the alcohol consumption are heavily disputed and a recommendation to use, for instance, anti-craving drugs would be inadequate considering the complexity of the issue. Nonetheless, GPs seem to perceive some advantages in using a pharmacological intervention and the question may be raised: What are those advantages and how can their understanding and a better understanding of GPs be used to improve BI? This question can hardly be answered easily. Some speculations may however be provided.

Firstly, GPs may prefer habitual behaviors [28]. Habitual behaviors are usually well-practiced, well-structured, and are mostly associated with lower risk of failure. Accordingly, GPs may be used to ending their treatment with prescribing a drug, leading to a preference for such a behavior. Time pressure and workload, quite common in general practice, may even facilitate the use of habitual behaviors. Secondly, GPs may prefer to maintain social control over the course of consultation. A drug can be prescribed in a predictable structured act without the risk of inducing a less controllable dispute about idiosyncratic barriers and costs of reducing alcohol consumption and the vague issue of a healthier lifestyle. Finally, GPs may prefer the pharmacological intervention based on their belief that such an intervention may be more effective than a mere verbal intervention like BI. They may, for instance, perceive that BI's effectiveness depends primarily on a patient's self-control in contrast to a pharmacological intervention influencing the organism more directly. Risky consumers are not disobedient in general and may know about the unhealthiness of their behavior. But they may have failed several times to achieve a lower consumption level leading to resignation and a low self-efficacy regarding their self-control.

There are some limitations to the present study. First, the GP's readiness to implement BI was compared with their readiness to implement a pharmacological intervention newly available in Germany and not very common. This intervention was used in the control condition because of being also designed to reduce the alcohol consumption of excessive drinkers. The comparison of the two interventions may be perceived as problematic for some reasons. Both interventions, BI and the pharmacological intervention, may include overlapping elements such as information and advice. They may furthermore differ in several associated aspects beyond the pure mean of intervention such as duration, effectiveness, or perceived eligibility regarding the target group. GPs may hence tend to prefer one of the two also for personal reasons based on their - probably 
heterogeneous - past experiences with these interventions. Both interventions should not be understood thus as equivalent or comparable solutions for the problem of excessive drinking. Because of their multiple differences it's impossible - based on our results - to attribute the GP's lower implementation readiness to specific aspects of BI. But this was not the intention of our investigation. It was the intention to compare the effect of the intervention type - BI versus another intervention with other characteristics for the same target group - with the effect of the financial reimbursement to show the greater relevance of the factor intervention type. And this was done. A second limitation was the recruitment of GPs based on voluntary participation should be noted implicating selection bias and the risk of results with limited representativeness. Voluntary participation was implemented by the Ethics Committee of the University of Halle and is a widespread practice in this field of research. Thirdly, the following aspects may limit the generalizability of our results. As a predictor of implementation readiness, we used the self-reported intention of GPs. Self-reports, especially regarding desired or recommended behaviors such as BI, are possibly biased towards social desirability and would hence indicate a higher readiness than will be shown in routine care. However, using intention as a predictor of future behavior is an accepted practice in psychological research [29]. Its predictive validity can be increased by using items specific to the context in question. This condition was met in our study. Moreover, GPs had to assess their implementation readiness based on written information about both interventions in the artificial context of case vignettes. Written information may provide a reduced and abstracted picture of the real conditions possibly inducing a weaker effect than real world conditions would do. Case vignettes are however a valid strategy to measure clinical competence [30]. Finally, it should be mentioned that other factors may have influenced our findings, such as GPs' concerns about the risk of stigmatization or a lack of skills. Future research should seek to clarify to what extent such factors, which have thus far been studied less, actually impair the GPs' readiness to implement SBI.

What are the implications for practical care? In Germany, primary care dependency prevention via SBI does not work effectively because all of the efforts to increase the GPs' use of SBI haven't been effective so far. Past research has emphasized that barriers may prevent GPs from implementing BI into routine care. It showed also that the elimination of barriers such as insufficient financial reimbursement did not lead to widespread implementation as may be expected [16] suggesting doubts regarding the belief that even a substantial increase of financial reimbursement would produce a primary care system with systematic screening of all patients and BI if screened positive. If inherent characteristics of BI are the problem its concept should be modified. Our results suggest the idea that inherent characteristics of BI may have a more negative effect on the implementation readiness of GPs than barriers such as an insufficient financial reimbursement. We show that GPs were more ready to treat an excessive drinker with a newly and even critically disputed pharmacological intervention than to use BI. Further research should investigate the crucial characteristics of BI to initiate a modification process finally leading to more effective primary care dependency prevention.

\section{Conclusions}

To explain the GPs' low readiness to implement SBI into routine care some crucial barriers, as for example insufficient financial reimbursement were identified by previous research. We showed for the first time that inherent characteristics of SBI had a more negative influence on the GPs' readiness than (insufficient) financial reimbursement. To test our assumption, we conducted a vignette study assessing the GPs' readiness to implement SBI in comparison to a pharmacological intervention also designed for the treatment of excessive drinkers in relation to standard or above-standard financial reimbursement. We conclude thus that even improved financial reimbursement will probably not lead to the intended outcome of a generally practiced implementation of SBI in general practice. Our results suggest a modification of the SBI-concept and its inherent characteristics.

\section{Supplementary information}

Supplementary information accompanies this paper at https://doi.org/10. 1186/s12875-020-01231-9.

\section{Additional file 1. \\ Additional file 2.}

\section{Abbreviations}

GP : General practitioner; GPS : General practitioners; SBI : Screening and brief intervention; $\mathrm{BI}$ : Brief intervention; PI : Pharmacological intervention; SAAP $\mathrm{PQ}$ : Short alcohol and alcohol problems perception questionnaire; AUDITC: Alcohol use disorders identification test; ANCOVA: Analysis of covariance

\section{Acknowledgements}

The authors thank the GPs for their participation in this study.

\section{Authors' contributions}

TF1 initiated the study, contributed to conception and design of the study, collected all data, and was responsible for data interpretation and drafting the manuscript. KS contributed to conception and design of the study. LP contributed to data interpretation and critically revised the manuscript. AK contributed to conception and design of the study. TF2 contributed to data interpretation and critically revised the manuscript. All authors approved the final version of the article.

\section{Funding}

The research project 'Hausärztliche Suchtprävention: Untersuchung motivationaler Barrieren gegen Maßnahmen zur Suchtprävention in der Hausarztpraxis' was funded by the Federal Ministry of Health in the amount of 51.185 euros. From this, the wages for scientific employees, the 
preparation of the investigation materials (e.g. questionnaires) and travel respectively conference costs were paid. The funding body had no influence whatsoever on the implementation of the research project, including study design, collection and interpretation of the data, and preparation of the manuscript. Open access funding provided by Projekt DEAL.

\section{Availability of data and materials}

The datasets used for the current study are available from the corresponding author on reasonable request.

\section{Ethics approval and consent to participate}

The ethics approval of the ethics committee of the Halle-Wittenberg Medical Faculty was added. All participants (GPs) were informed about the study by a formal cover letter explaining the background of our research and the anonymized and statistically aggregated analysis of all data. Participation in the study was completely voluntary. With the signing of the consent form, the participants gave their written consent to participate in the study.

\section{Consent for publication}

Not applicable, as the manuscript does not contain any individual persons data.

\section{Competing interests}

The authors declare that they have no competing interests. The Author Thomas Frese is a member of the editorial board of the journal.

Received: 18 May 2020 Accepted: 22 July 2020

Published online: 19 August 2020

\section{References}

1. Kaner EFS, Beyer FR, Muirhead C, Campbell F, Pienaar ED, Bertholet N, Daeppen JB, Saunders JB, Burnand B. Effectiveness of brief alcohol interventions in primary care populations. Cochrane Database Syst Rev. 2018;(2):CD004148. https://doi.org/10.1002/14651858.CD004148.pub4.

2. Grothues JM, Bischof G, Reinhardt S, Meyer C, John U, Rumpf HJ. Effectiveness of brief alcohol interventions for general practice patients with problematic drinking behavior and comorbid anxiety or depressive disorders. Drug Alcohol Depend. 2008;94(1-3):214-20.

3. Babor TF, Higgins-Biddle J, Saunders J, Monteiro M. AUDIT The Alcohol Use Disorders Identification Test: Guidelines for use in primary care. Second ed. Geneva: World Health Organisation; 2001

4. Beich A, Gannik D, Malterud K. Screening and brief intervention for excessive alcohol use: qualitative interview study of the experiences of general practitioners. BMJ. 2002;325(7369):870.

5. Heather N. Can screening and brief intervention lead to population-level reductions in alcohol-related harm? Addict Sci Clin Pract. 2012;7(1):15.

6. O'Regan A, Cullen W, Hickey L, Meagher D, Hannigan A. Is problem alcohol use being detected and treated in Irish general practice? BMC Fam Pract. 2018;19(1):30.

7. Sebo P, Cerutti B, Fournier JP, Rat C, Rougerie F, Senn N, et al. How do general practitioners put preventive care recommendations into practice? A crosssectional study in Switzerland and France. BMJ Open. 2017;7(10):e017958.

8. Aalto M, Pekuri P, Seppa K. Obstacles to carrying out brief intervention for heavy drinkers in primary health care: a focus group study. Drug Alcohol Rev. 2003;22(2):169-73.

9. Anderson P, Kaner E, Wutzke S, Funk M, Heather N, Wensing M, et al. Attitudes and managing alcohol problems in general practice: an interaction analysis based on findings from a WHO collaborative study. Alcohol Alcohol. 2004;39(4):351-6.

10. Fankhänel T, Lenz J, Papert $\mathrm{S}$, Voigt $\mathrm{K}$, Klement A. Screening und Brief Intervention in der Hausarztpraxis: Barrieren gegen eine Frühintervention bei Patienten mit Alkoholmissbrauch. Psychother Psychosom Med Psychol. 2014;64(9/10):373-7.

11. Johnson M, Jackson R, Guillaume L, Meier P, Goyder E. Barriers and facilitators to implementing screening and brief intervention for alcohol misuse: a systematic review of qualitative evidence. J Public Health (Oxf) 2011:33(3):412-21.

12. Keurhorst MN, Anderson P, Spak F, Bendtsen P, Segura L, Colom J, et al. Implementing training and support, financial reimbursement, and referral to an internet-based brief advice program to improve the early identification of hazardous and harmful alcohol consumption in primary care (ODHIN): study protocol for a cluster randomized factorial trial. Implementation Sci : IS. 2013:8:11.

13. Nilsen P. Brief alcohol intervention--where to from here? Challenges remain for research and practice. Addiction. 2010;105(6):954-9.

14. Nygaard P, Paschall MJ, Aasland OG, Lund KE. Use and barriers to use of screening and brief interventions for alcohol problems among Norwegian general practitioners. Alcohol Alcohol. 2010;45(2):207-12.

15. Rapley T, May C, Frances KE. Still a difficult business? Negotiating alcoholrelated problems in general practice consultations. Soc Sci Med. 2006;63(9): 2418-28.

16. Anderson P, Coulton S, Kaner E, Bendtsen P, Kloda K, Reynolds J, et al. Delivery of brief interventions for heavy drinking in primary care: outcomes of the ODHIN 5-country cluster randomized trial. Ann Fam Med. 2017;15(4):335-40.

17. Coleman AL, Seitzman RL, Cummings SR, Yu F, Cauley JA, Ensrud KE, et al. The association of smoking and alcohol use with age-related macular degeneration in the oldest old: the study of osteoporotic fractures. Am J Ophthalmol. 2010;149(1):160-9.

18. Town R, Kane R, Johnson P, Butler M. Economic incentives and physicians' delivery of preventive care: a systematic review. Am J Prev Med. 2005;28(2):234-40.

19. Burke $B L$, Arkowitz $H$, Menchola M. The efficacy of motivational interviewing: a meta-analysis of controlled clinical trials. J Consult Clin Psychol. 2003:71(5):843-61.

20. Palpacuer C, Duprez R, Huneau A, Locher C, Boussageon R, Laviolle B, et al. Pharmacologically controlled drinking in the treatment of alcohol dependence or alcohol use disorders: a systematic review with direct and network meta-analyses on nalmefene, naltrexone, acamprosate, baclofen and topiramate. Addiction. 2018;113(2):220-37.

21. Mann K, Hoch E, Batra A. S3-Leitlinie Screening, Diagnose und Behandlung alkoholbezogener Störungen. Berlin, Heidelberg: Springer Verlag; 2016.

22. Johansen KGV, Tarp S, Astrup A, Lund H, Pagsberg AK, Christensen R. Harms associated with taking nalmefene for substance use and impulse control disorders: a systematic review and meta-analysis of randomised controlled trials. PLoS One. 2017:12(8):e0183821.

23. Einheitlicher Bewertungsmaßstab (EBM) (2018)

24. Anderson P, Clement S. The AAPPQ revisited: the measurement of general practitioners' attitudes to alcohol problems. Br J Addict. 1987;82(7):753-9.

25. Gunzerath L, Faden V Zakhari S, Warren K. National Institute on Alcohol Abuse and Alcoholism report on moderate drinking. Alcohol Clin Exp Res. 2004;28(6):829-47.

26. Abidi L, Nilsen P, Karlsson N, Skagerström J, O'Donnell A. Conversations about alcohol in healthcare - cross-sectional surveys in the Netherlands and Sweden. BMC Public Health. 2020:4:20(1):283.

27. Dzidowska M, Lee KSK, Wylie C, Bailie J, Percival N, Conigrave JH, et al. A systematic review of approaches to improve practice, detection and treatment of unhealthy alcohol use in primary health care: a role for continuous quality improvement. BMC Fam Pract. 2020;13;21(1):33.

28. Verplanken B. Beyond frequency: habit as mental construct. Br J Soc Psychol. 2006:45(Pt 3):639-56.

29. Glasman LR, Albarracin D. Forming attitudes that predict future behavior: a meta-analysis of the attitude-behavior relation. Psychol Bull. 2006;132(5): 778-822.

30. Kathiresan J, Patro BK. Case vignette: a promising complement to clinical case presentations in teaching. Educ Health. 2013;26(1):21-4.

\section{Publisher's Note}

Springer Nature remains neutral with regard to jurisdictional claims in published maps and institutional affiliations.

Ready to submit your research? Choose BMC and benefit from:

- fast, convenient online submission

- thorough peer review by experienced researchers in your field

- rapid publication on acceptance

- support for research data, including large and complex data types

- gold Open Access which fosters wider collaboration and increased citations

- maximum visibility for your research: over $100 \mathrm{M}$ website views per year

At BMC, research is always in progress.

Learn more biomedcentral.com/submissions 